\title{
Utilization of thermal bands of Landsat 8 data and geographic information system for analysis of urban heat island in Baghdad governorate 2016
}

\author{
Alaa Khalaf $^{1, *}$ \\ ${ }^{1}$ Ministry of Science and Technology, Baghdad, Iraq
}

\begin{abstract}
This study aimed to determine Urban Heat Island in Baghdad Governorate capital of Iraq by thermal bands of Landsat 8 images and Geographic Information System. Two cloud free Landsat 8 scenes covering the study area were selected for analysis. These scenes were located at path 168/37 and path 169/37. Images were acquired during daytime at 10:33 AM and it were dated August 19, 2016 and August 26, 2016, respectively. All images mentioned above were registered in Universal Transverse Mercator projection zone 38. Temperatures have been extracted from thermal bands 10 and 11 for each scene and then these results have been merged by mosaic process to produce one scene for band 10 and band 11 . Finally, urban heat island has been extracted for study area by taking the average temperatures of band 10 and band 11. The final results shown that Baghdad Governorate contains four heat islands: water body, built-up area, green area, and bare land area. The Heat Island of bare land was highest, followed by green area, built-up area and water body. The highest summer daytime Heat Island was found on bare land $\left(57^{\circ} \mathrm{C}\right)$, followed by green area $\left(45{ }^{\circ} \mathrm{C}\right)$, built-up area $\left(43{ }^{\circ} \mathrm{C}\right)$, and water body $\left(37{ }^{\circ} \mathrm{C}\right)$.
\end{abstract}

\section{Introduction}

Most urban areas have been created at a quickened rate all over the world, in both developing and developed nations. Urban development and improvement reduces the normal land cover and replaces it with another front of synthetic components (e.g. structures, roads, modern regions, and so forth.). As need be, the nearby atmosphere of these refers to changes by new land utilization and cover modifications which has made the Urban Heat Island (UHI) [1].

It is outstanding and recorded that urbanization can affect nearby climate. An urban warmth island is a metropolitan region which is essentially hotter than its encompassing provincial ranges. Higher urbanization prompts more particular urban warmth island with tremendous temperature contrasts amongst urban and provincial regions [2]. The climate of the city impressions of natural warmth created is because of the variety in the dissemination of surface temperatures between the scopes of the city and complexities. The qualities of the stream of warm radiation, which drives low spillage warm radiation of the surface into space, as a result of the gradual addition of structures or developed region to build the heat of the roads. Then again getting to be focused on urban communities and the urban

\footnotetext{
* Corresponding author: alaaspace1@yahoo.com
}

region inside which are hotter than its edges in the appearance is known as Urban Heat Island [3].

The power of the UHI depends on a few parameters. The most imperative variable is the warmth affected from sun, while the built up is extremely hot during the evening contrasted and day time. Other factors include atmospheric conditions; when the environment has cloudless skies and sunlight, winds conditions, etc. The framework or geometry of the city and geology of the land assume a critical part, yet primarily in the spatial appropriation of temperatures in the city. At last the emanation of anthropogenic warmth consequences for the UHI power though its effect is weaker and it depends upon the season [4]. Many studies have demonstrated that air temperatures in downtown amid the night are by and large higher than air temperatures in encompassing country regions. Urban Warmth Island is commonly present at daytime and evening time, yet have a tendency to be higher amid the night. On a midyear day, the sun can warm dry, uncovered urban surfaces, for example, asphalts and rooftops, to a temperature more blazing than the air temperature. The soggy surfaces in country environment remain mostly near air temperatures. The normal contrast in daytime temperature between the urban and provincial zones is $5^{\circ} \mathrm{C}$ to $10^{\circ} \mathrm{C}$, and the distinctions in evening time temperature is $10^{\circ} \mathrm{C}$ to $15^{\circ} \mathrm{C}$ considered higher than the daytime distinction [1].This study has been used in the Landsat 8 , and GIS for 
deriving urban heat islands and to determine the thermal island peak more effectively in Baghdad Governorate in 2016.

\section{Reasons for urban heat island}

There are various causes which add to the arrangement of Urban Heat Island. The causes which assume critical part in the formation of UHI are described below [5].

\subsection{Low albedo materials}

Albedo is assessed by the proportion of the reflected sun powered vitality to the occurrence sunlight based vitality. On the off chance that the albedo of the urban surface is low, it will store more sun based vitality and the expanding of urban temperature.

\subsection{Human gathering}

As the human get-together is noticeable at the downtown areas inferable from the accessibility of different offices, discharge of $\mathrm{CO}_{2}$ is more in these zones. $\mathrm{CO}_{2}$ stores warm upgraded climatic temperature. A definitive impact is that it aids the arrangement of Warmth Island as it were.

\subsection{Destruction of trees}

Trees capture the sun oriented warmth and furthermore assimilate $\mathrm{CO}_{2}$ for their own photosynthesis, making the earth cool. With the annihilation of vegetation, the productivity of chilling framework goes drastically off causing formation of the procedure.

\subsection{Urban canopy}

The heat reflected by a building is caught by the closeby taller structures which are known as the urban canopy. UHI is exacerbated with the arrangement of urban canopy.

\subsection{Wind blocking}

Because of the nearness of thickly arranged structures, wind speed is lessened. Accordingly, the cooling impact by convection reduces, consequently the warmth caught, can't be extinguished, resulting in escalation of the impact.

\subsection{Air pollutant}

In the urban territories, particularly in the downtown area, air contamination is prominent. Fumes from vehicles and mechanical contaminations discharged in the earth, trap sun powered radiation along these lines leading to higher temperatures and the microclimate impact ends up noticeably more grounded. The causes are summarized in the Figure (1).

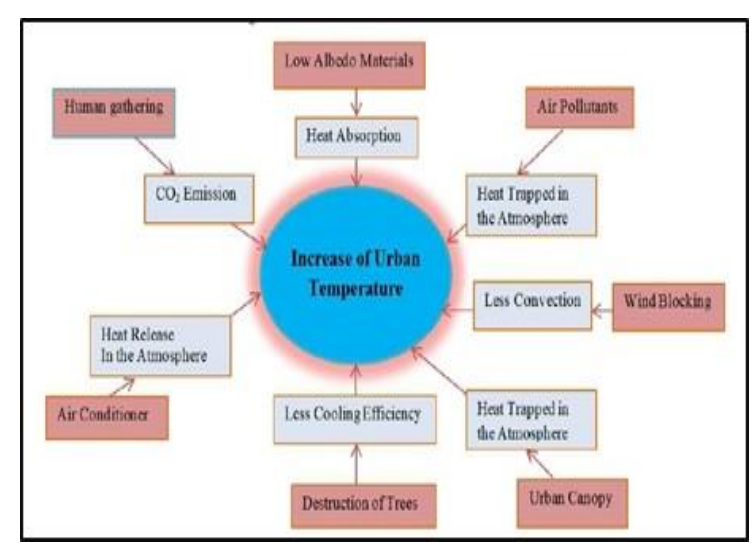

Fig.1. Urban Heat Island formation

\section{Methodology}

The urban heat island map of study area has been produced by the following procedures:

\subsection{Determination satellite image data}

The study area is covered by two scenes of the Landsat 8 , the first scene is located at path168/row37 and the second scene is located at path169/raw37.These scenes are acquired during daytime at 10:33 $\mathrm{AM}$ and it is dated August 19, 2016 and August 26, 2016 respectively.

\subsection{Registration of satellite images}

Satellite images (two scenes) are geometrically corrected in the datum The World Geodetic System 1984 and UTM projection zone $38 \mathrm{~N}$ using the first order of polynomial function.

\subsection{Mosaic images and extract study area}

The satellite images are merged by using mosaic process and then the study area is extracted from them.

\subsection{Producing urban heat island}

ARCGIS 10.2 spatial model tool is used to produce Urban Heat Island (UHI) for study area depending on thermal bands 10 and 11 for Landsat .

\subsection{The model is performed by the following steps}

3.5.1 Conversion from Digital Number (DN) to radiance 
Landsat thermal bands 10 and 11 are converted from DN to Radiance for all scenes (mentioned above in step 1) which depend on its metadata files.

\subsubsection{Conversion from radiance to temperature degrees}

Results in the last step is converted to temperature Kelvin degrees and then subtract 273 from the Kelvin degrees to convert it into Celsius degrees

3.5.3 Band 10 (Celsius degrees) for path 168/37 and path 169/37 is merged by mosaic process

3.5.4 Band 11 (Celsius degrees) for path 168/37 and path $169 / 37$ is merged by mosaic process

3.5.5 Final step is performed by taking average of results of last two steps and extract final Urban Heat Island for study area

\section{Study area}

The study area is Baghdad Governorate in center of Iraq. The study area is bounded by the coordinate (from $43^{\circ}$ $50^{\prime}$ to $44^{\circ} 55^{\prime}$ ) East and (from $32^{\circ} 48^{\prime}$ to $33^{\circ} 45^{\prime}$ ) North in zone $38 \mathrm{~N}$ according to Geographic coordinate system. The selected area could be recognized in Figure (2).

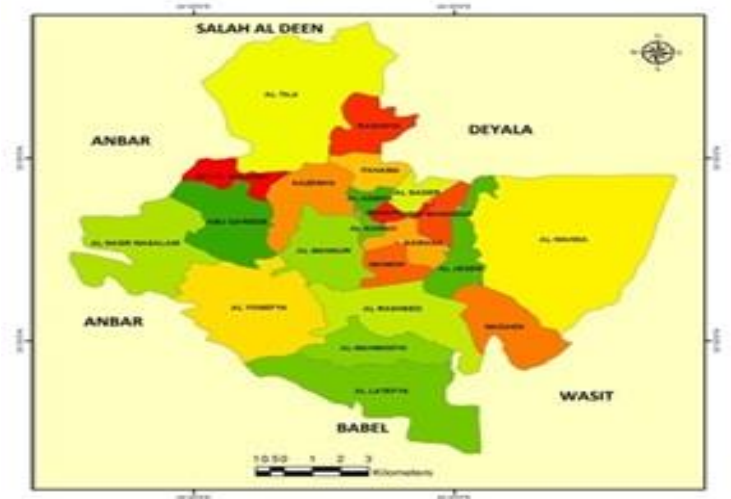

Fig.2. Map of study area modify by author (source surveying foundation 2010)

\section{Materials and methods}

\subsection{Soft-ware packages}

ArcGIS 10.2 has been used to process, manage, and analyze the raster and thematic data sets in this research .

\subsection{Satellite Images data}

The study area is covered by two scenes of the Landsat 8 as illustrated in Figures 3 and 4. Multispectral Landsat (path $168 /$ row37 and path $169 /$ row37) are dated August 19, 2016 and August 26, 2016 respectively; imagery remotely sensed data-sets were assembled to Urban Heat Island analysis in the study area by using thermal bands 10 and 11 with spatial resolution $100 \mathrm{~m}$.

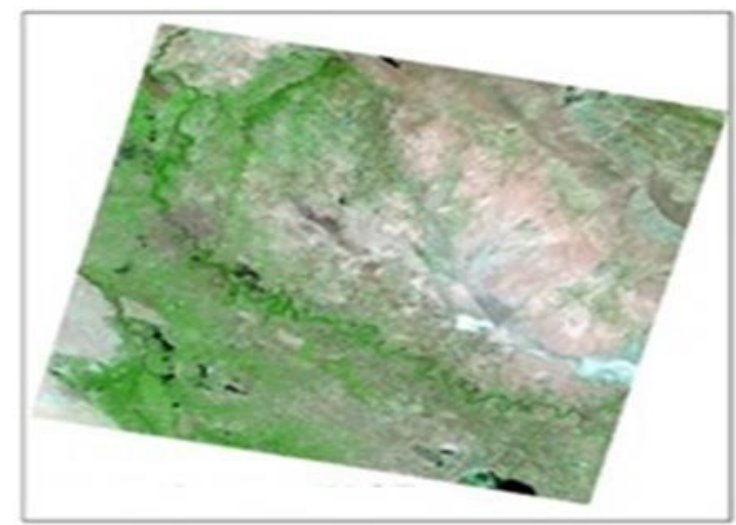

Fig.3. first scene of study area 2016.

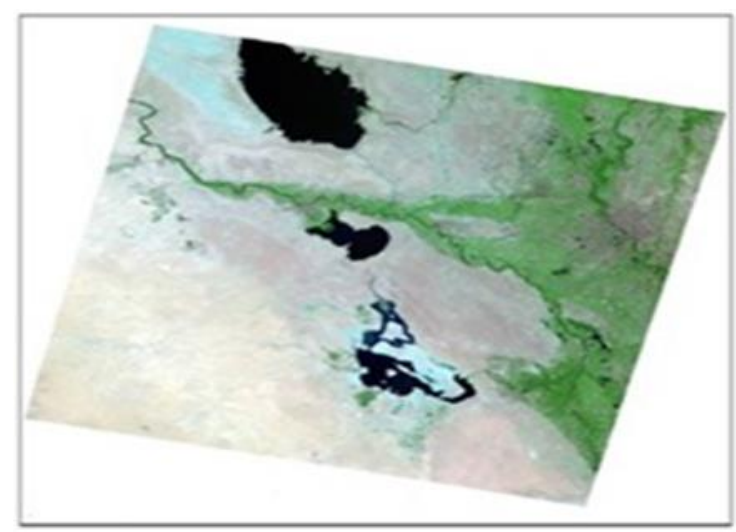

Fig.4. second scene of study area 2016

\subsection{Pre-processing}

The data preprocessing is performed utilizing ArcGIS 10.2 program .Each Landsat 8 scene is composed of the independent single layer images. Thus, it is firstly used to combine the single-layer images to a multi-layer image of Landsat 8 using a layer composite tool. Secondly, the geometric correction was made for the Landsat 8 images, by which each point on the image would have latitude and longitude geographical coordinates with datum WGS84. This is the most important step in pre-processing. Finally, the image subset function was utilized to cut our study area as outlined in Figure 5. 


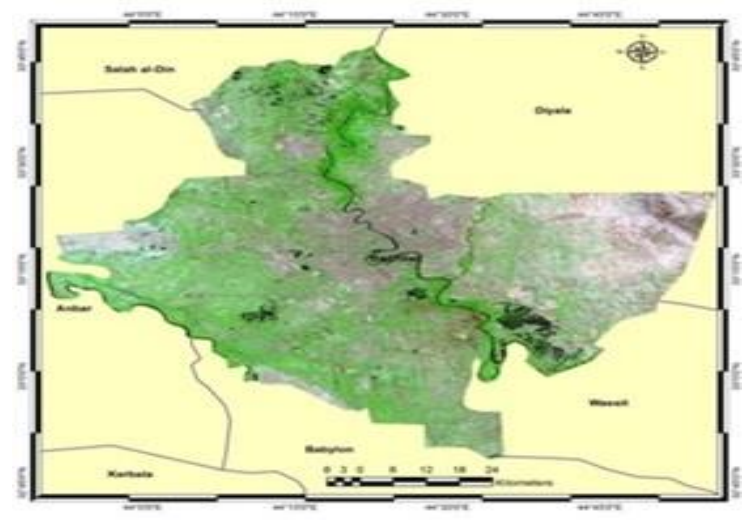

Fig.5. image of study area august 2016 (color composite 6, 4, 3)

\subsection{Image processing and analysis}

In satellite images, each pixel value is represented as digital numbers (DN) changing for each sensor type. In determination of Urban Heat Island for study area from Landsat 8 , the digital number of image pixels should be changed into spectral radiance utilizing the sensor adjustment information in order to acquire helpful values. As one of the most widely used software packages in the field of digital image processing, the spatial modeler in ARCGIS package gives a powerful tool to fulfill most image processing functions. The spatial model to recover UHI from Landsat 8 information utilizing ARCGIS spatial model apparatus is composed. In this model, the Landsat 8 thermal bands 10 and 11 are used. These two bands are then converted to Urban Heat Island as illustrated in Figures 6 and 7 according to USGS 2013 Equation 1; digital numbers were converted to spectral radiances $(\mathrm{L} \lambda)$.

$$
L \lambda=M L^{*} Q \mathrm{cal}+A L
$$

Where:

$L \lambda=$ Spectral radiance $[W /(m 2 * s r . * \mu m)]$

$M L=$ Radiance multiplicative scaling factor for the band (Radiance Multi Band $\mathrm{n}$ from the metadata).

$A L=$ Radiance additive scaling factor for the band (Radiance Add Band $\mathrm{n}$ from the metadata).

$Q c a l=\mathrm{L} 1$ pixel value in $\mathrm{DN}$

In the final stage of the processing, urban heat island (UHI) was calculated with the simplified formula (2) (USGS, 2013).

$$
T=K 2 / \ln (K 1 / L \lambda+1)
$$

Where:

$T=$ TOA Brightness Temperature, in Kelvin.

$L \lambda=$ Spectral radiance $[$ Watts $/(m 2 * s r . * \mu m)]$

$K 1=$ Thermal conversion constant for the band (K1 constant band $\mathrm{n}$ from metadata)

$K 2=$ Thermal conversion constant for the band $(K 2$ constant band $\mathrm{n}$ from metadata)

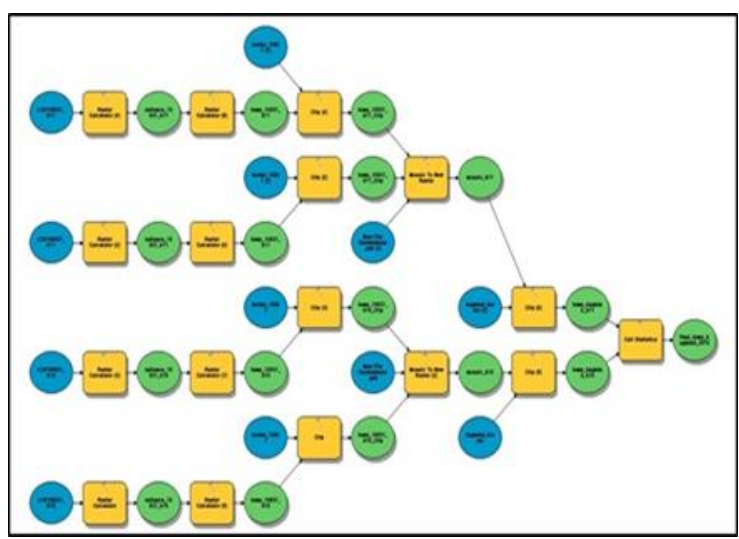

Fig.6. spatial model processing to convert DN to UHI

\section{Results and discussion}

The study has utilized thermal band of Landsat 8 for extracting urban heat island for region of study, GIS incorporated with satellite images helped in distinguishing the urban heat Island tops in Baghdad Governorate. For the most part Urban Heat Island force has been discovered based on distinction between the temperature of the urban zone and the surrounding zones. The results have shown that Baghdad Governorate contains four heat islands: water body, built-up area, green cover and non-vegetation or bare land cover as illustrated in Figure 7. The Heat Island of bare land was highest, followed by green area, built-up area and water body was lower. The highest summer daytime Heat Island was found on bare land $\left(57^{\circ} \mathrm{C}\right)$, followed by green area $\left(45^{\circ} \mathrm{C}\right)$, built-up area $\left(43^{\circ} \mathrm{C}\right)$ and water $\left(37^{\circ} \mathrm{C}\right)$.

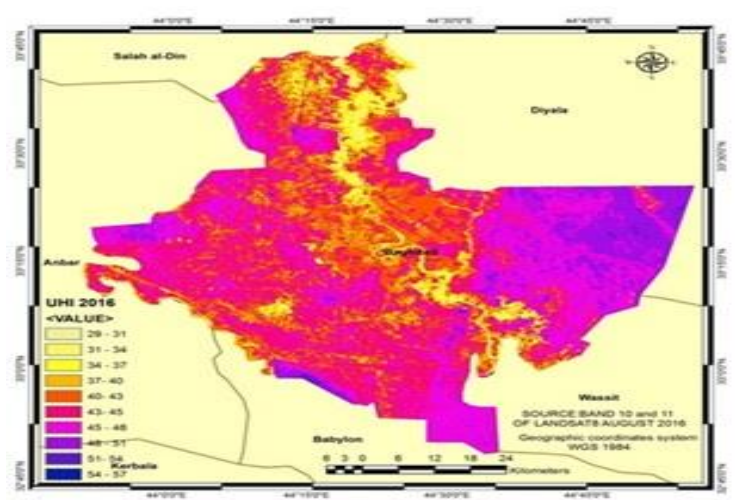

Fig.7. Urban Heat Island for Baghdad Governorate August 2016

\section{Conclusions}

1. GIS Spatial modeler gives a capable apparatus to achieve most image processing capacities.

2. Urban Heat Island helps to remove merging problem between built-up and bare land area.

3 . The results illustrate that study area contains four heat islands viz.: water body, built-up area, green cover and non-vegetation or bare land cover. 
4. The results illustrate that Heat Island of bare land was highest, followed by green area, built-up area and finally, water body. The highest summer daytime Heat Island was found on bare land $\left(57^{\circ} \mathrm{C}\right)$, followed by green area $\left(45^{\circ} \mathrm{C}\right)$, built-up area $\left(43^{\circ} \mathrm{C}\right)$ and water $\left(37^{\circ} \mathrm{C}\right)$.

\section{References}

1.N. Khalid, Urban Heat Island in Erbil City, M.sc Thesis, Department of Physical Geography and Ecosystems Science, Lund University, Sweden (2014)

2 .L. Liu and Y. Zhang, J. Remote Sens. 3, 1536 (2011)

3. M. Almutairi, J. Geos. \& Envi.Protec. 3, 19 (2015)

4. J. Montavez, A. Rodriguez, J. Jimenez, Int. J. Climatol. 20,900 (2000)

5. Md. Nuruzzaman, In. J. Environmental Monitoring \& Analysis, 3, 68 (2015) 